\title{
IL- $10^{+}$NK and TGF- $\beta^{+}$NK cells play negative regulatory roles in HIV infection
}

Yongjun Jiang ${ }^{1}$, Mei Yang ${ }^{1}$, Xiaojuan Sun ${ }^{1,3}, X_{i}$ Chen $^{1}$, Meichen Ma ${ }^{1}$, Xiaowan Yin ${ }^{1}$, Shi Qian ${ }^{1}$, Zining Zhang ${ }^{1,2}$, Yajing $\mathrm{Fu}^{1}$, Jing Liu', Xiaoxu Han ${ }^{1,2}$, Junjie $X u^{1,2}$ and Hong Shang ${ }^{1,2^{*}}$

\begin{abstract}
Background: Natural killer (NK) cells play cytotoxic roles by targeting tumor cells or virus infected cells, they also play regulatory roles by secreting cytokines and chemokines. Transforming growth factor (TGF)- $\beta$ and interleukin (IL)-10 are important immunosuppressive cytokines potentially related to the immune dysregulation that occurs in the infection of human immunodeficiency virus (HIV). NK cells are an important source of TGF- $\beta$ and a main early producer of IL-10 in response to viral infection. Here, we evaluated the percentages of IL-10+ and TGF- $\beta^{+}$NK cells in HIV-infected patients relative to healthy controls (HCs).
\end{abstract}

Methods: Study participants $(n=63)$ included 31 antiretroviral treatment (ART)-naïve HIV-infected patients, 17 ART-treated HIV-infected patients, and 15 HIV-negative HCs. Expression of IL-10 or TGF- $\beta$ in NK cells was examined by flow cytometry, and the influences of recombinant IL-10 (rlL-10) or recombinant TGF- $\beta$ (rTGF- $\beta$ ) on NK cell function were investigated in vitro.

Results: Compared with HCS, ART-naïve HIV-infected patients had increased percentages of IL-10 $(2.0 \%$ vs. $0.4 \%, p=0$. $015)$ and TGF- $\beta^{+}(4.5 \%$ vs. $2.1 \%, p=0.022)$ NK cells, and ART-treated patients also had a higher percentage of IL-10 ${ }^{+} \mathrm{NK}$ cells $(2.5 \%$ vs. $0.4 \%, p=0.002)$. The percentages of IL-1 $0^{+}$and TGF- $\beta^{+}$NK cells were positively correlated $(r=0.388 ; p=0$. 010). The results of in vitro experiments demonstrated that rlL-10 and rTGF- $\beta$ inhibited NK cell CD107a expression ( $p=$ 0.037 and $p=0.024$, respectively), IFN- $\gamma$ secretion ( $p=0.006, p=0.016$, respectively), and granzyme $B$ release after stimulation ( $p=0.014, p=0.040$, respectively).

Conclusions: Our data suggest that the percentages of IL-10 $0^{+}$or TGF- $\beta^{+}$NK cells are increased in HIV-infected patients, and that rlL-10 and/or rTGF- $\beta$ can inhibit NK cell functions in vitro, providing a potential therapeutic target for strategies aimed at combating HIV infection.

Keywords: HIV, IL-10, TGF- $\beta$, NK, Antiretroviral treatment, IFN- $\gamma$, Immune regulation

\section{Background}

Natural killer (NK) cells serve as the first line of immune defense in host protection against viruses and tumors [1]. In humans, NK cells account for $2 \%-18 \%$ of the lymphocytes in peripheral blood and express various inhibitory and activating receptors, including C-type lectin-like, natural cytotoxicity, and killer cell immunoglobulin-like receptors

\footnotetext{
* Correspondence: hongshang100@hotmail.com

'Key Laboratory of AIDS Immunology of National Health and Family Planning Commission, Department of Laboratory Medicine, The First Affiliated

Hospital, China Medical University, No. 155, Nanjingbei Street, Heping District, Shenyang, Liaoning Province 110001, China

${ }^{2}$ Collaborative Innovation Center for Diagnosis and Treatment of Infectious

Diseases, 79 Qingchun Street, Hangzhou, China

Full list of author information is available at the end of the article
}

$[2,3]$. NK cell functions include killing target cells, cytokine production, and antibody-dependent cellular cytotoxicity (ADCC) [2]. Moreover, NK cells are critical effectors mediating cytotoxicity, and regulators modulating the activation and development of other immune response components [1]. NK cells are identified via their lack of CD3 and expression of CD56 cell surface markers, and they can be further divided into CD56 $6^{\text {dim }}$ and CD56 $6^{\text {bright }}$ subsets [3]. Generally, CD56 ${ }^{\text {dim }}$ NK cells release perforin or granzymes, which play a key role in killing target cells, whereas CD56 ${ }^{\text {bright }}$ NK cells secrete interleukin (IL)-10, interferon (IFN)- $\gamma$, transforming growth factor (TGF)- $\beta$ and other cytokines, to exert immunomodulatory effects [4-6]. 
IL-10 and TGF- $\beta$ are important immunoregulatory cytokines in vivo $[7,8]$, which suppress adaptive and innate immunity [9]. IL-10 is produced by multiple cell types, including T cells, NK cells, monocytes, and B cells; NK cells are a major early source of this cytokine in response to viral infection [10-13]. IL-10 is involved in the impairment of $\mathrm{T}$ cell function during persistent viral infections, and blockage of the IL-10 pathway alone is sufficient to restore $\mathrm{T}$ cell activities and increase viral control [14]. TGF- $\beta$ is also secreted by various cell types, particularly NK cells, which are the only lymphocyte population that constitutively produces this cytokine [15]. TGF- $\beta$ plays important roles in immunomodulation, inflammation, and tissue repair [16], and can inhibit $\mathrm{T}$ cell proliferation and cytotoxicity [17]. IL-10 is reported to cause harmful effects during human immunodeficiency virus (HIV) infection by reducing IL-2 and IL-12 production, thereby inhibiting antigen-presentation and cellular immune responses [18-20]. HIV-infected $\mathrm{CD}^{+}{ }^{+} \mathrm{T}$ cells can produce IL-10, leading to persistent viral infection [11]. High levels of TGF- $\beta$ in the plasma were reported in HIV-infected patients compared with healthy controls (HCs) [21]; however, the cell types producing TGF- $\beta$ in this context remain to be determined.

IL- $10^{+} \mathrm{NK}$ cells play significant modulatory roles in various viral, bacterial, and parasitic infections [12, 22-24]. TGF- $\beta^{+}$NK cells have been reported to serve as an important co-stimulatory signal to induce suppressive T cells [15]. In HIV infection, multiple cells can produce IL-10 and TGF- $\beta$. The majority of research has focused only on $\mathrm{T}$ cells, rather than NK cells, which are a major source of these cytokines and play important roles during acute HIV infection. The percentage of IL- $10^{+}$or TGF- $\beta^{+}$NK cells in HIV-infected patients and the regulatory effect of IL-10 and TGF- $\beta$ have yet to be elucidated.

In the present study, we determined the percentages of IL- $10^{+}$and TGF- $\beta^{+}$NK cells in HIV-infected patients and healthy controls (HCs). We also explored the immunomodulatory effects of recombinant IL-10 (rIL-10) and recombinant TGF- $\beta$ (rTGF- $\beta$ ) on NK cell functions, including the expression of lysosomal-associated membrane glycoprotein-1 (LAMP1; also known as $\mathrm{CD} 107 \mathrm{a})$, and IFN- $\gamma$ secretion. The results indicated that IL- $10^{+}$and TGF- $\beta^{+}$NK cells may be risk factors for HIV disease progression, and are potential therapeutic targets in combating HIV infection.

\section{Methods}

\section{Study participants}

Sixty-three individuals participated in this study, including 31 antiretroviral treatment-naïve HIV-infected patients (ART-naïve), 17 ART-treated HIV-infected patients (ART-treated), and 15 HIV-negative HCs. The 31 ART-naïve patients had a median $\mathrm{CD} 4^{+} \mathrm{T}$ cell count of 363 cells/ $\mu$ l (interquartile range [IQR] 277-421 cells/ $\mu \mathrm{l}$ ) and median viral load of 24,760 copies/ml (range, 374-388,000 copies/ml). ART-naïve patients were further grouped according to $\mathrm{CD} 4^{+} \mathrm{T}$ cell counts $\left(\mathrm{CD} 4^{+} \mathrm{T} \geq\right.$ or $<$ 350 cells $/ \mu$ groups) or viral load (viral load $>10^{4}$ or $\leq 10^{4}$ copies/ml groups). The 17 ART-treated patients had received ART for $\geq 2$ years, and had undetectable viral loads (HIV RNA, <20 copies/ml); the median duration of their virologic suppression at the time of sampling was 33 months (IQR: 24-60 months), and they had a median $\mathrm{CD}_{4}{ }^{+} \mathrm{T}$ cell count of 586 cells/ $\mu \mathrm{l}$ (IQR: $453-684$ cells/ $\left.\mu \mathrm{l}\right)$. HCs were HIV-negative, anti-hepatitis $\mathrm{C}$ antibodynegative, and hepatitis $B$ surface antigen-negative, with normal liver and kidney functions, and without immunesystem diseases.

\section{Detection of IL- $10^{+}$or TGF- $\beta^{+}$NK cells by flow cytometry}

Peripheral blood mononuclear cells (PBMCs) were isolated from HIV-infected patients and HCs by Ficoll ${ }^{\text {Tx }}$ density gradient centrifugation. PBMCs were cultured for $6 \mathrm{~h}$ with recombinant IL-12 (rIL-12, $10 \mathrm{ng} / \mathrm{ml})$ and recombinant IL-15 (rIL-15, $50 \mathrm{ng} / \mathrm{ml}$ ) in a $5 \% \mathrm{CO}_{2}$ incubator at $37{ }^{\circ} \mathrm{C}$. Total NK cells and NK cell subsets were defined by their expression of CD3 and CD56, detected using the anti-CD3 PerCP and anti-CD56 PE-Cy7 antibodies (BD Biosciences, San Jose, CA, USA), respectively. Cells were stained with intracellular anti-TGF- $\beta$-PE and anti-IL-10-APC (Biolegend, San Diego, CA, USA) and fixed in 1\% paraformaldehyde before detection using a flow cytometer (LSR II; Becton Dickinson, Franklin Lakes, NJ, USA) and analysis with FACSDiva ${ }^{\mathrm{Tm}}$ software (Becton Dickinson); the gating strategy is shown in Fig. 1.

\section{Determination of NK cell CD107a expression and IFN- $\gamma$ secretion}

PBMCs were co-cultured with different concentrations of rIL-10 and/or rTGF- $\beta$ for $5 \mathrm{~h}$, then stimulated with rIL-12 (10 ng/ml, R\&D) and rIL-15 (50 ng/ml, R\&D) for $24 \mathrm{~h}$ at $37^{\circ} \mathrm{C}$, and anti-CD107a-PE antibody (Biolegend, San Diego, CA, USA) added simultaneously. Cells were co-cultured in GolgiStop ${ }^{\text {tw }}$ ((Becton Dickinson) for $\geq 5$ h before the end of stimulation. PBMCs were collected, and anti-CD3-Percp and anti-CD56-PE-cy7 were used for surface staining. Cells were then stained for intracellular IFN- $\gamma$ with anti-IFN- $\gamma$-APC antibody (BD Biosciences, San Jose, CA, USA), washed with phosphate-buffered saline, and fixed in $1 \%$ paraformaldehyde, followed by analysis using the LSR II flow cytometer.

\section{Determination of NK cell release of granzyme B and perforin}

PBMCs were co-cultured with different concentrations of rIL-10 and/or rTGF- $\beta$ for $5 \mathrm{~h}$. Then, cells were stimulated with PMA (10 $\mathrm{ng} / \mu \mathrm{L})$ and ionomycin $(1 \mu \mathrm{g} / \mu \mathrm{L}$ ) (Sigma 

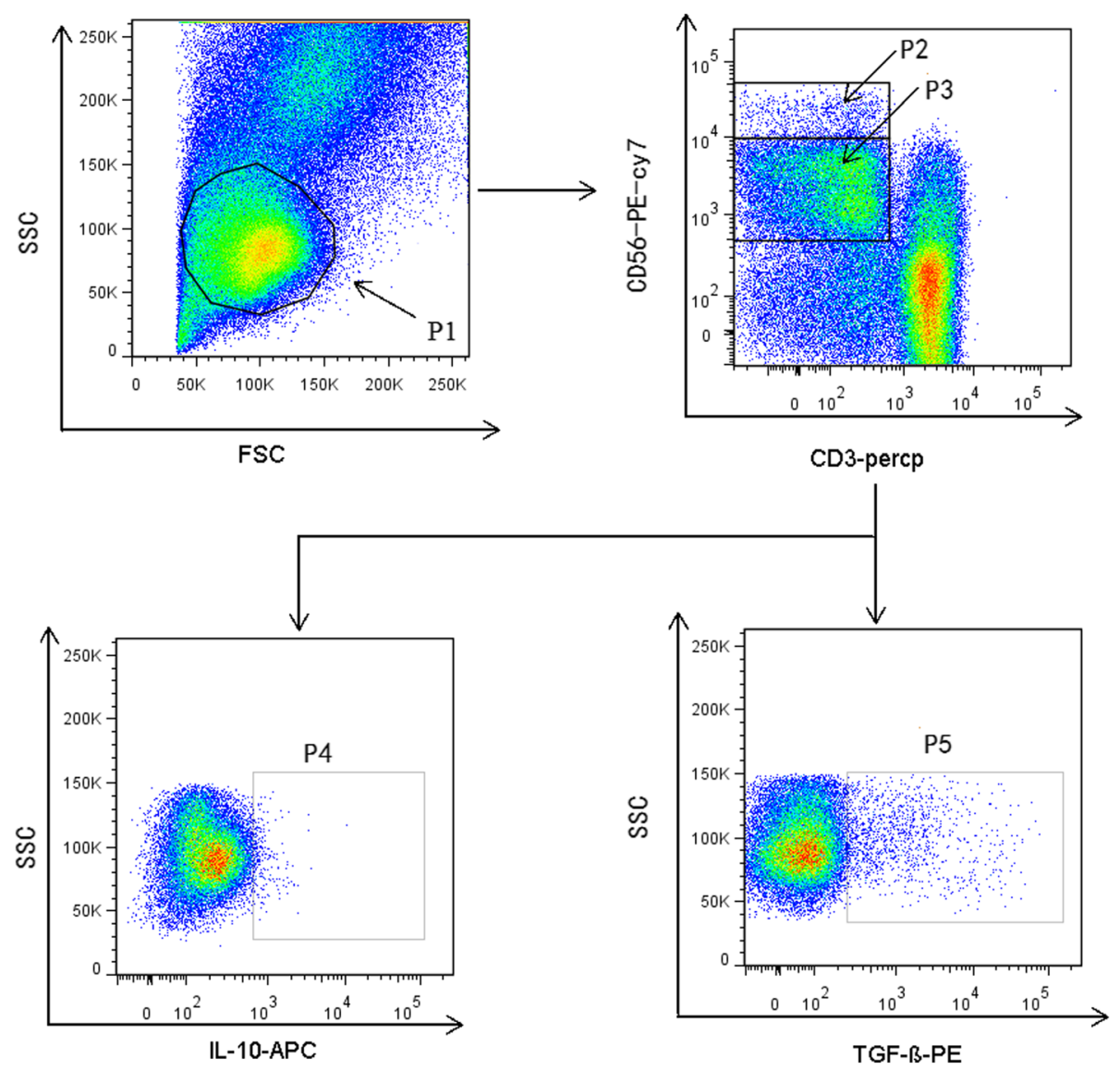

Fig. 1 Gating strategy for identification of NK cells and their subsetsP1 represents lymphocytes identified using a side and forward scatter dot plot. P2 represents CD56 $6^{\text {bright }} \mathrm{NK}$ cells; gating, CD3- CD56 $6^{\text {bright }}$. P3 represents CD56 ${ }^{\text {dim }}$ NK cells; gating, CD3 ${ }^{-}$CD56 ${ }^{\text {dim }}$. P2 + P3 represents total NK cells. P4 represents $\mathrm{IL}-10^{+}$NK cells. P5 represents TGF- $\beta^{+}$NK cells

Chemical St. Louis, MO, USA) for $6 \mathrm{~h}$ at $37^{\circ} \mathrm{C}$. PBMCs were collected, and surface-stained with anti-CD3-PerCP and anti-CD56-PE-Cy7. Anti-granzyme B-PE and anti-perforin-fluorescein isothiocyanate (FITC) (BD Biosciences, San Jose, CA, USA) were used for intracellular staining, and cells detected by flow cytometry (LSR II).

\section{Detection of $\mathrm{CD}^{+}{ }^{+} \mathrm{T}$ cell count}

$\mathrm{CD}_{4}{ }^{+} \mathrm{T}$ cell counts were determined using a flow cytometer (FACS Calibur; Becton Dickinson). High, medium, and low Trucount ${ }^{\mathrm{tm}}$ Control Beads (BD Biosciences, San Jose, CA, USA) were used to confirm the accuracy and quality of $\mathrm{CD} 4^{+} \mathrm{T}$ cell counts. A single-platform lyse-nowash procedure was conducted with TriTEST ${ }^{\mathrm{Tm}}$ anti-CD3PerCP/CD4-FITC/CD8-PE reagents and Trucount tubes (BD Biosciences, San Jose, CA, USA) according to the manufacturer's instructions.

\section{Determination of HIV viral load}

Plasma HIV RNA levels were determined with by reverse transcription-polymerase chain reaction (RT-PCR) using the $\mathrm{COBAS}^{\circ}$ AmpliPrep $^{\circ} / \mathrm{COBAS} \mathrm{TaqMan}^{\mathrm{Tm}}$ HIV test v2.0 (Roche Diagnostic Systems, Basel, Switzerland). The detection range of this method is $20-10,000,000$ copies $/ \mathrm{ml}$. The number of HIV RNA copies was calculated according to the manufacturer's reference standard.

\section{Statistical analyses}

The non-parametric Mann-Whitney $U$-test was used for evaluation of differences between two groups, and the Kruskall-Wallis test employed for comparisons of multiple groups. The Friedman's test was used for multiple pairwise comparisons. Correlation analysis was performed using the Spearman's rank correlation test. All analyses were undertaken using SPSS v19.0 (IBM, Armonk, NY, USA). $p<0.05$ was considered significant.

\section{Results}

Percentages of total NK cells and NK subsets in HIV-infected patients and HCs

The clinical characteristics of ART-naive and ARTtreated patients, and HCs, are presented in Table 1. The sex and age of HIV-infected patients were matched with 
Table 1 Clinical characteristics of study subjects

\begin{tabular}{llll}
\hline Parameters & $\mathrm{HC}(n=15)$ & ART-naive patients $(n=31)$ & ART-treated patients $(n=17)$ \\
& Median(IQR) & Median(IQR) & Median(IQR) \\
\hline Sex & male & male & male \\
Age(years) & $27(25-33)$ & $25(21-37)$ & $30(27.5-38)$ \\
CD4 ${ }^{+}$T cells (cells/Ml) & ND & $363(277-421)$ & $586(453-684)$ \\
HIV Viral Load(copies/ml) Log10 & NA & $4.19(3.87-4.86)$ & Undetectable $(<1.30)$ \\
Months since infection & NA & $33(19-68)$ & $67(40.5-86.5)$ \\
Months of ART treatment & NA & NA & $42(30-66)$ \\
\hline
\end{tabular}

NOTE: ND: no data; NA: not applicable

those of HCs. The percentages of total NK cells and NK subsets among lymphocytes in peripheral blood samples from the three groups were measured by flow cytometry.

The percentages of total NK cells in ART-naïve and ART-treated patient samples were lower than that in HCs $(p=0.014, p=0.024)$ (Fig. 2a). In addition, the percentages of $\mathrm{CD} 56^{\mathrm{dim}} \mathrm{NK}$ cells in ART-naïve patients were lower than those in HCs $(p=0.006)$ (Fig. 2b) and there was a tendency towards lower percentages of CD56 ${ }^{\text {bright }}$ NK cells in ART-naïve patients compared with those of HCs $(p=0.067)$ (Fig. 2c).

\section{Percentages of IL- $10^{+}$or TGF- $\beta^{+}$NK cells in HIV-infected patients}

PBMCs obtained from HCs, and ART-naïve, and ARTtreated patients, were stimulated with rIL-12 and rIL-15. The percentage of IL- $10^{+}$or TGF- $\beta^{+}$NK cells was examined by intracellular staining and multi-color flow cytometry. Representative flow cytometry plots of IL-10 or TGF- $\beta$ expression in NK cells from each participant group are shown in Fig. 3a. The percentage of IL-10 NK cells in ART-naïve patients was higher than that in $\mathrm{HCs}(p=0.015)$; moreover, the percentage of IL- $10^{+} \mathrm{NK}$ cells was also higher in the ART-treated HIV patient group than that in HCs $(p=0.002)$ (Fig. 3b). The percentage of TGF- $\beta^{+}$NK cells in ART-naïve patients was elevated compared with that of HCs $(p=0.022)$, while in ART-treated patients, the percentage of TGF- $\beta^{+}$NK cells still exhibited a tendency to be higher than that of HCs $(p=0.060)$ (Fig. 3c). There was no difference in the percentage of IL-10 ${ }^{+}$CD $56^{\text {dim }}$ NK cells among the three groups (Fig. 3d), whereas the percentage of TGF- $\beta^{+}$ CD56 ${ }^{\text {dim }}$ NK cells in ART-naïve patients was higher than that in HCs $(p=0.024)$ (Fig. 3e). Moreover, there were no differences in the percentages of $\mathrm{IL}-10^{+} \mathrm{CD} 56^{\text {bright }}$ and TGF- $\beta^{+}$CD $56^{\text {bright }}$ NK cells among the three groups (Fig. 3f, g). In ART-naïve patients, the percentage of IL- $10^{+}$NK cells was positively correlated with that of TGF- $\beta^{+}$NK cells $(r=0.388, p=0.010)$ (Fig. 3h) and the percentage of IL- $10^{+}$CD56 ${ }^{\mathrm{dim}}$ NK cells correlated positively with that of TGF- $\beta^{+}$CD56 ${ }^{\text {dim }}$ NK cells $(r=0.438$, $p=0.003$ ) (Fig. 3i).

Comparison of the percentages of IL- $10^{+}$and TGF- $\beta^{+}$NK cells in different groups according to $\mathrm{CD}^{+} \mathrm{T}$ cell count or HIV viral load

$\mathrm{CD}^{+} \mathrm{T}$ cell counts and viral loads are important markers for HIV disease progression. We analyzed the correlation between the percentage of $\mathrm{IL}-10^{+}$or TGF- $\beta^{+}$ NK cells and $\mathrm{CD}^{+}{ }^{+} \mathrm{T}$ cell counts and viral loads and found no significant correlations between them. Furthermore,
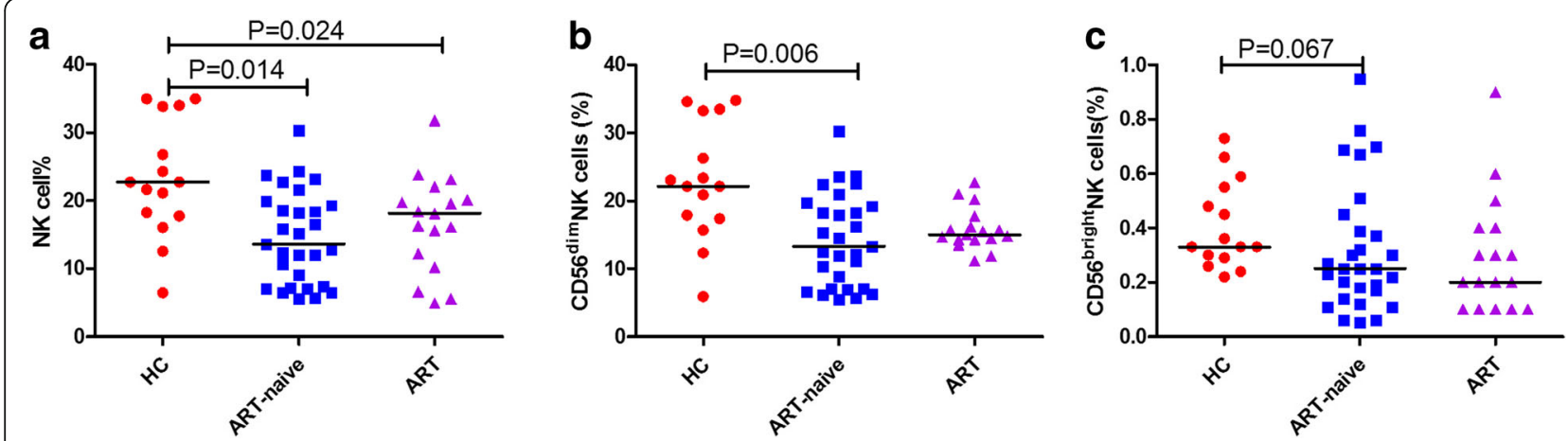

Fig. 2 Percentages of total NK cells and NK cell subsets in HIV-infected patients and HCs The percentages of total NK cells among lymphocytes from HCs, ART-naïve, and ART-treated patients (a). The percentages of NK cell subsets (CD56 ${ }^{\text {dim }}$ and CD56 $6^{\text {bright }}$ ) in lymphocytes from HCs, ART-naïve, and ART-treated patients $(\mathbf{b}, \mathbf{c})$ 


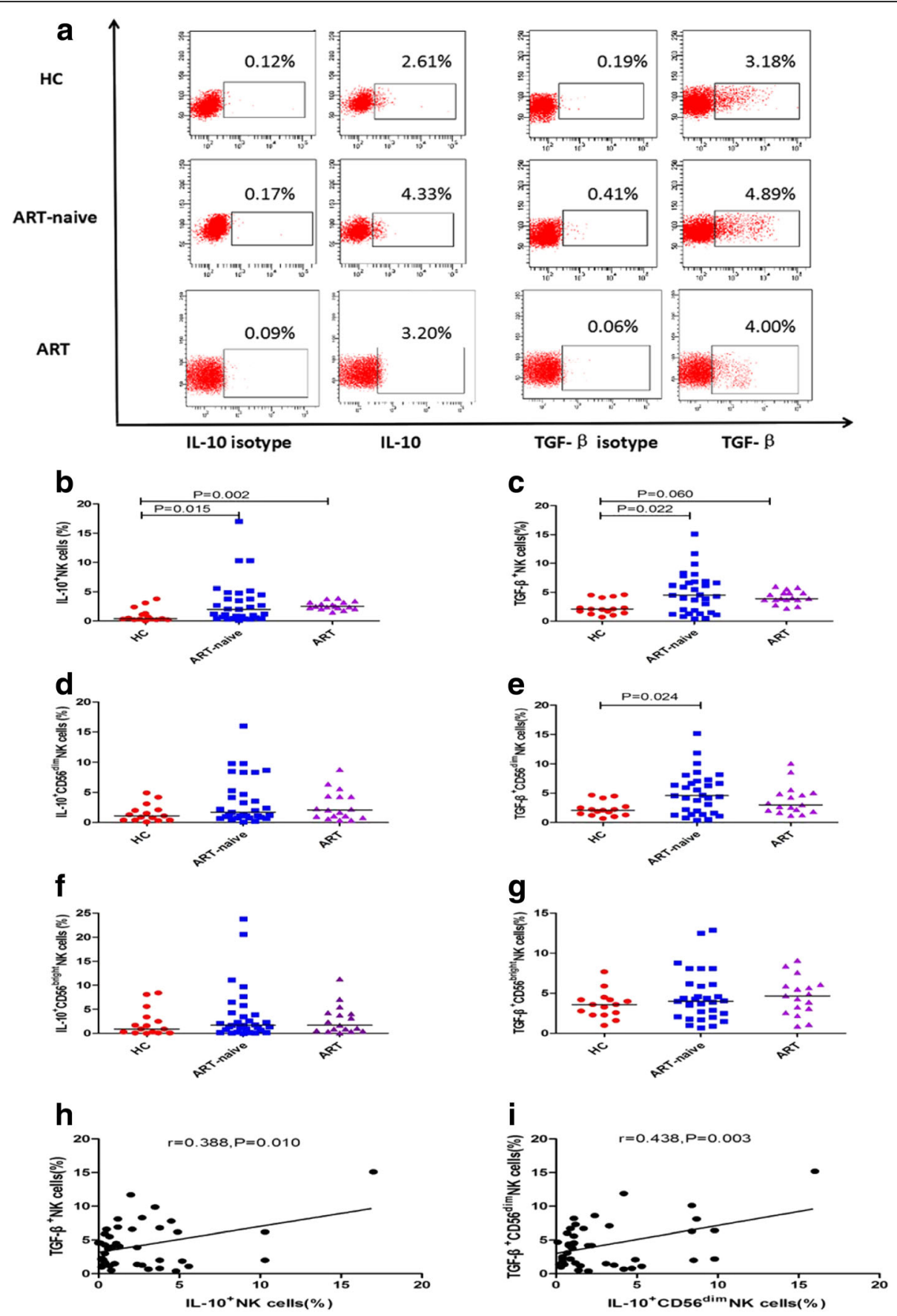

Fig. 3 Comparison of the percentages of $\mathrm{IL}-10^{+}$and TGF- $\beta^{+}$NK cells in HIV-infected patients and HCsPBMCs from HCs, ART- naiive, and ART-treated patients were stimulated using $\mathrm{rlL}-12(10 \mathrm{ng} / \mathrm{ml})$ and $\mathrm{rlL}-15(50 \mathrm{ng} / \mathrm{ml})$. IL-10 $10^{+}$and TGF- $\beta^{+} \mathrm{NK}$ cells were examined by multi-color flow cytometry, with gates defined according to isotype controls. Representative flow-cytometric plots of IL-10 $0^{+}$and TGF- $\beta^{+}$NK cells in HIV-infected

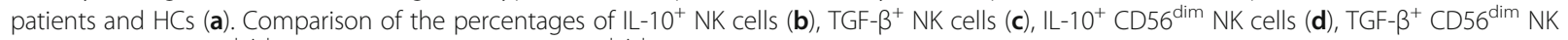
cells (e), IL-10 $0^{+}$CD56 bright NK cells (f), and TGF- $\beta^{+}$CD56 ${ }^{\text {bright }}$ NK cells $(\mathbf{g})$, among the three groups. Correlation between the percentage of IL-10 ${ }^{+}$ NK cells and TGF- $\beta^{+}$NK cells $(\mathbf{h})$. Correlation between the percentage of $1 L-10^{+}$CD56 dim NK cells and TGF- $\beta^{+}$CD56 $6^{\text {dim }}$ NK cells (i)

we analyzed groups subdivided by $\mathrm{CD} 4^{+} \mathrm{T}$ cell count or viral load. The percentage of IL- $10^{+} \mathrm{NK}$ cells in the $\mathrm{CD} 4^{+}$ $\mathrm{T}<350$ cells $/ \mu$ l group of ART-naïve patients was higher than that of the HC group $(p=0.032)$, and there was an increasing trend in the $\mathrm{CD} 4^{+} \mathrm{T} \geq 350$ cells/ $\mu$ l group of ART-naïve patients compared with $\mathrm{HCs}(p=0.075)$ (Fig. 4a). There was no difference in the percentages of TGF- $\beta^{+}$NK cells among groups (Fig. 4b). When grouped 

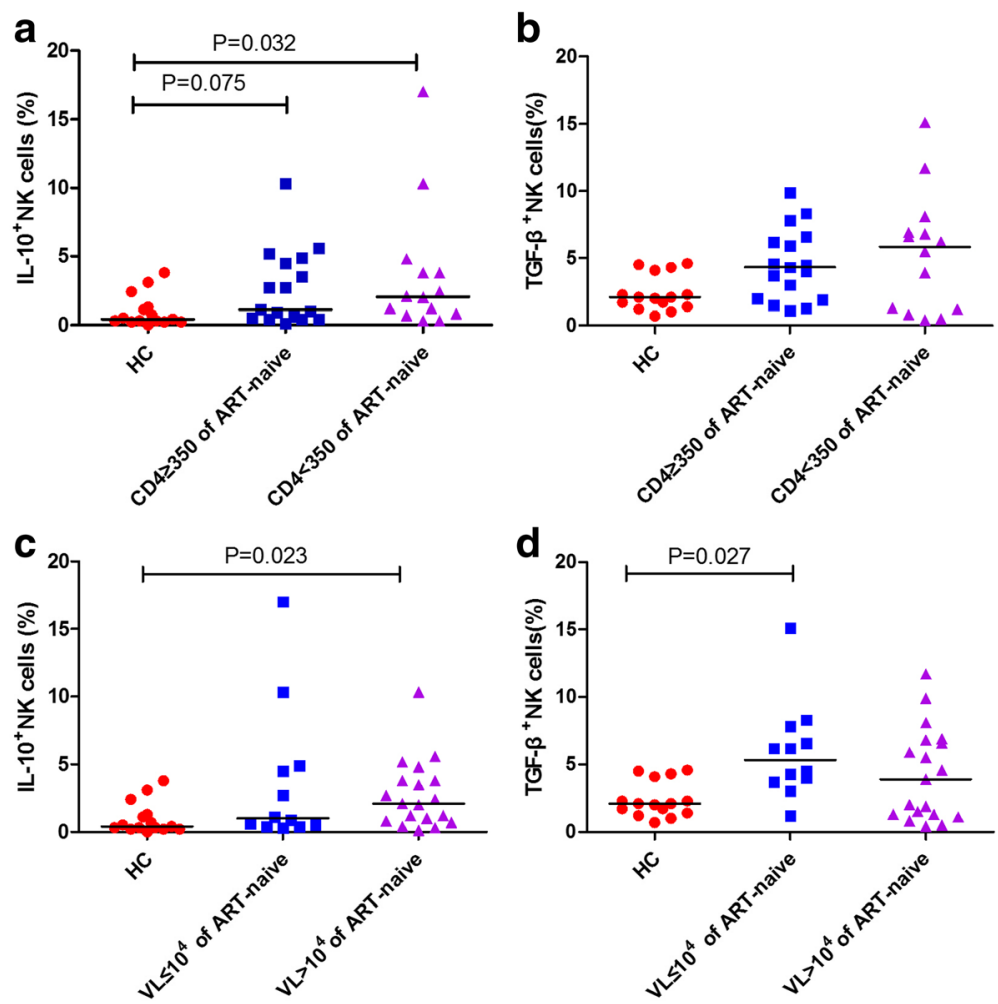

Fig. 4 Percentage of $\mathrm{IL}-10^{+}$or TGF- $\beta^{+}$NK cells in different groupsThe percentage of IL-10 $10^{+}$or TGF- $\beta^{+}$NK cells in different groups according to CD4 ${ }^{+} \mathrm{T}$ cell counts $(\mathbf{a}, \mathbf{b})$. The percentage of $\mathrm{IL}-10^{+}$or TGF- $\beta^{+}$NK cells in different groups according to viral load $(\mathbf{c}, \mathbf{d})$

according to the level of viral load, the percentage of IL- $10^{+}$NK cells in ART-naïve patients with viral load > $10^{4}$ copies $/ \mathrm{ml}$ was higher than that in the $\mathrm{HC}$ group ( $p=$ 0.023 ) (Fig. 4c), and that in the group with viral load $<10^{4}$ copies $/ \mathrm{ml}$, while the percentage of TGF- $\beta^{+}$NK cells was higher than that in the $\mathrm{HC}$ group $(p=$ 0.027) (Fig. 4d).

\section{Effect of rlL-10 and rTGF- $\beta$ on the NK cell CD107a expression and IFN- $\gamma$ secretion}

The expression of CD107a and IFN- $\gamma$ secretion can be used to assess the functional anti-viral ability of NK cells. The inhibitory effects of rIL-10 or rTGF- $\beta$ on NK cell functions were evaluated, and the percentages of IFN $-\gamma^{+}$and $\mathrm{CD} 107 \mathrm{a}^{+}$NK cells determined. Representative flow cytometry plots, demonstrating the effects of rIL-10 or rTGF- $\beta$ on CD107a expression by NK cells are presented in Fig. 5a. CD107a expression in NK cells was inhibited by high concentrations of rIL-10 or rTGF- $\beta$ in vitro $(p=0.037, p=0.024)$, and the rate of inhibition increased gradually with increasing concentrations of these cytokines (Fig. 5b, c). Moreover, the effect of rIL-10 and rTGF- $\beta$ on CD107a expression in NK cells was synergistic, demonstrating inhibitory effects much greater than those of either cytokine individually $(p=0.006)$ (Fig. $5 \mathrm{~d}$ ).
Representative flow-cytometric plots demonstrating the effects of rIL-10 or rTGF- $\beta$ on IFN- $\gamma$ secretion from NK cells are shown in Fig. 6a. IFN- $\gamma$ secretion by NK cells was also inhibited by rIL-10 or $\operatorname{rTGF}-\beta$ ( $p=$ $0.006, p=0.016)$, and the rate of inhibition increased gradually with their concentrations (Fig. 6b, c). Again, the effect of both IL-10 and TGF- $\beta$ was synergistic $(p=0.006)$ (Fig. 6d).

\section{Effects of rIL-10 and rTGF- $\beta$ on granzyme B and perforin release by NK cells}

Granzyme B and perforin are important functional markers for NK cells, which indicate the killing capability of NK cells. The percentages of $\mathrm{IL}-10^{+}$and TGF- $\beta^{+}$ NK cells were elevated in HIV infected patients; however, their influence on the release of granzyme B and perforin by NK cells is not known. Our results demonstrate that a low concentration of rIL-10 or rTGF- $\beta$ did not inhibit the release of granzyme B, whereas high concentrations of either cytokine did inhibit the release of this factor $(p=0.014, p=0.040)$ (Fig. 7a, b). A synergistic effect of rIL-10 and rTGF- $\beta$ on inhibition of the release of granzyme B was also noted ( $p=0.037)$ (Fig. 7c). Similarly, rIL-10 and rTGF- $\beta$ inhibited perforin release by NK cells (Fig. 8a-c). 


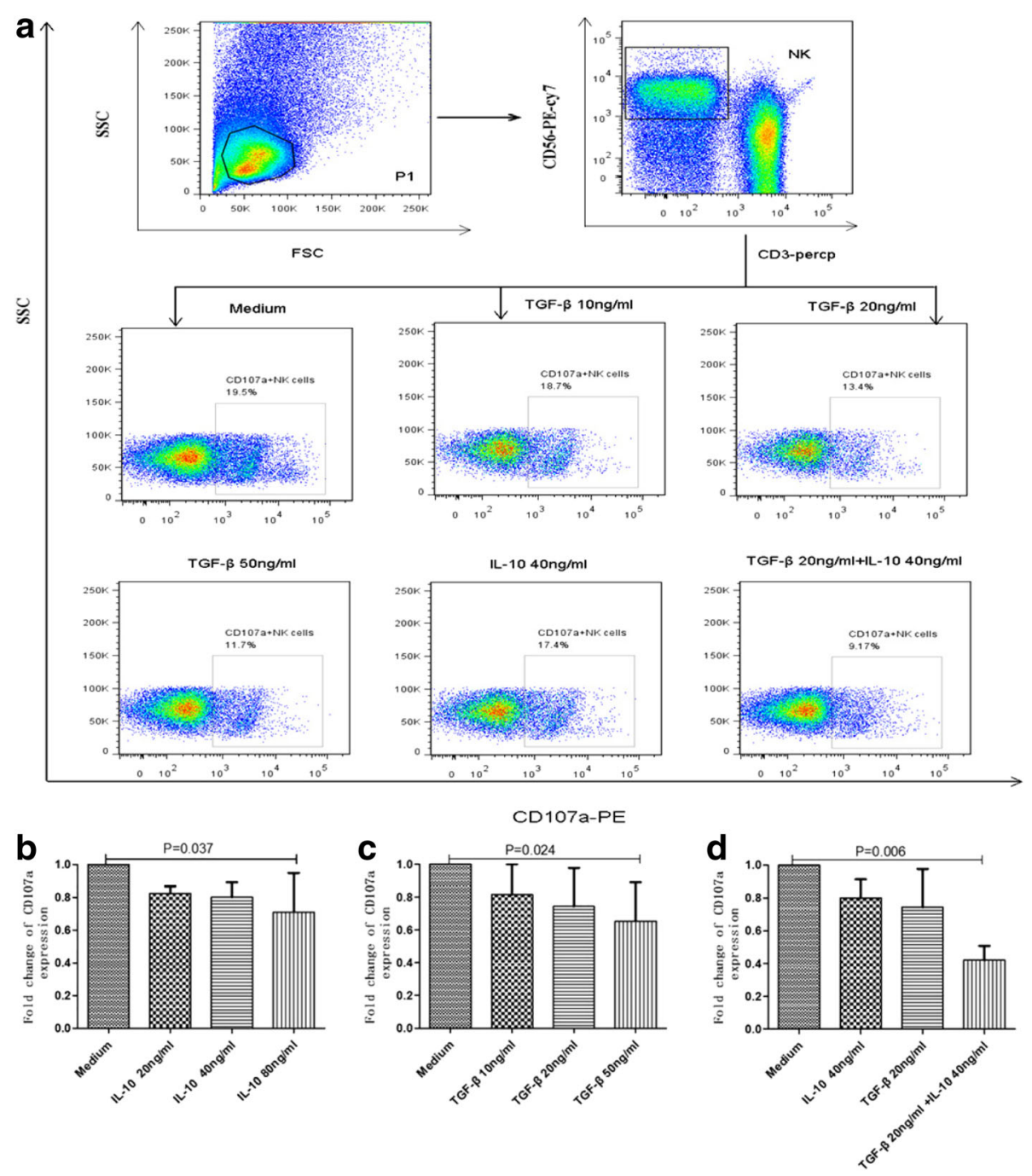

Fig. 5 Effect of rlL-10 and rTGF- $\beta$ on CD107a expression in NK cellsPBMCs were incubated with rlL-10 or rTGF- $\beta$ and CD107a expression by NK cells evaluated. Representative flow-cytometry plots demonstrated the effect of rlL-10 or rTGF- $\beta$ on CD107a expression in NK cells (a). CD107a expression by NK cells was inhibited by different concentrations of rlL-10 (b) or rTGF- $\beta$ (c). Fold-change in CD107a expression by NK cells was synergistically inhibited by rIL-10 and rTGF- $\beta$ (d). Fold-change of CD107a expression = (percentage CD107a expression in untreated controls percentage of CD107a expression after treatment with rlL-10 and/or rTGF- $\beta$ )/percentage of CD107a expression in untreated controls

\section{Discussion}

Regulation of the immune system has attracted considerable attention over the last decade, and the cytokines, IL-10 and TGF- $\beta$, have important roles in controlling immune processes. The suppression of anti-cancer immunity by TGF- $\beta$ and IL-10 has been reported in several studies [25-28]. In breast cancer, circulating levels of $\mathrm{IL}-10^{+}$and TGF- $\beta^{+}$NK cells are increased, which inhibits the production of the NK cell effectors, IFN- $\gamma$ and $\mathrm{CD} 107 \mathrm{a}$, and promotes the migration and invasion of breast-cancer cells [9].

Brockman et al. reported that IL-10 mRNA levels were increased in several PBMC subpopulations in HIVinfected patients compared with $\mathrm{HCs}$, particularly $\mathrm{T}$ cells, B cells, monocytes, and NK cells, and that the inhibition of the IL-10 pathway enhanced the proliferative capacity of $\mathrm{T}$ cells [29]. Based on these findings regarding the levels of IL-10 mRNA in NK cells, we further explored the intracellular secretion of IL-10 and TGF- $\beta$ proteins in NK cells (total and subsets) and investigated the relationship between $\mathrm{IL}-10^{+} / \mathrm{TGF}-\beta^{+} \mathrm{NK}$ cells and $\mathrm{CD} 4^{+} \mathrm{T}$ cell counts/viral loads. Our data elucidate the effects of IL-10 and TGF- $\beta$ on NK cell functions, including IFN- $\gamma$ secretion, CD107a expression, and granzyme B or perforin release.

We found that ART-naïve patients had elevated percentages of $\mathrm{IL}-10^{+} \mathrm{NK}$ cells relative to $\mathrm{HCs}$; however, patients who had received ART, also had higher percentages of IL- $10^{+}$NK cells than those of HCs. Comparisons of TGF- $\beta^{+}$NK cell percentages among study groups 


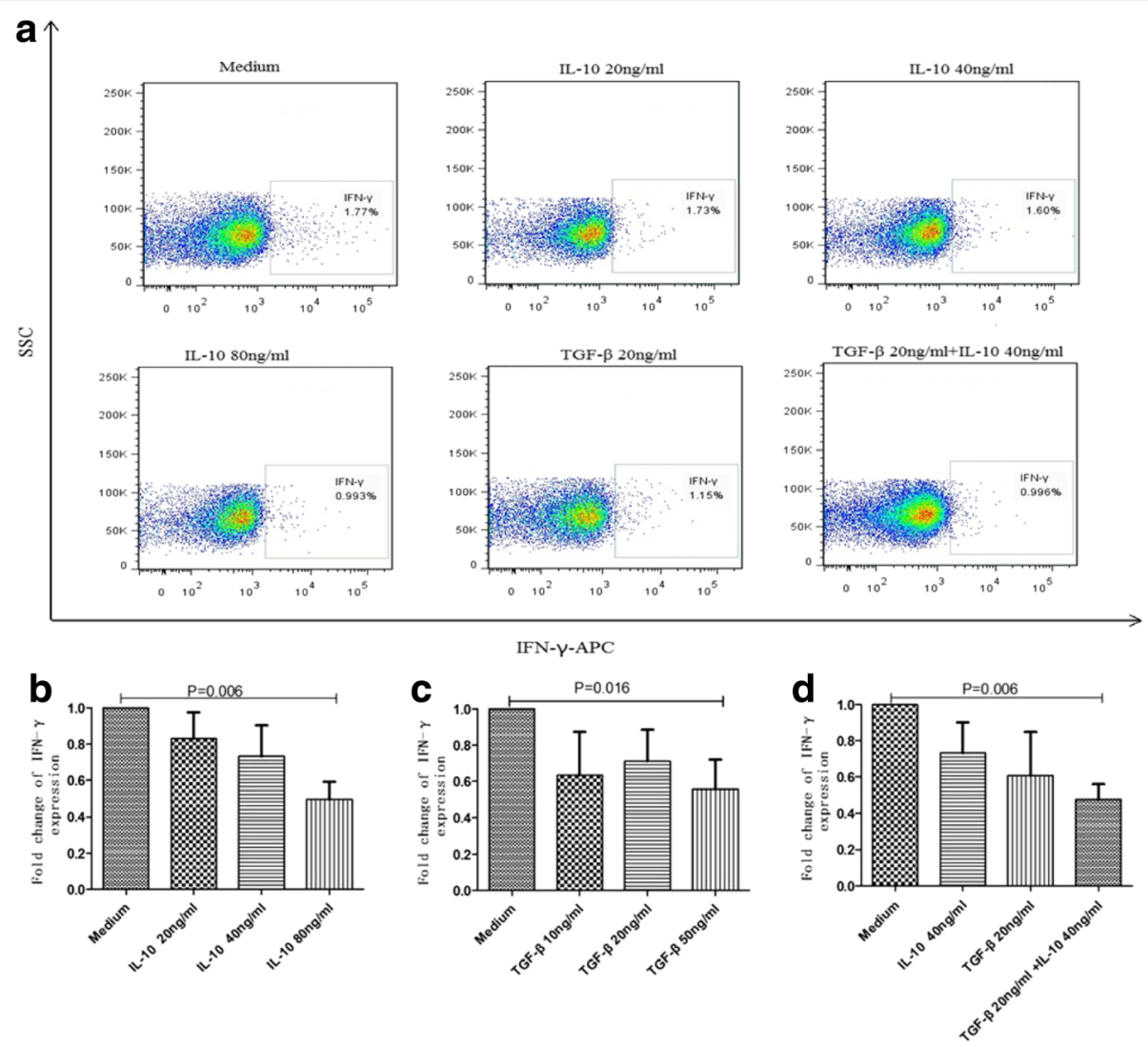

Fig. 6 Effect of rlL-10 and rTGF- $\beta$ on IFN- $\gamma$ secretion by NK cellsPBMCs were co-cultured with rlL-10 and/or rTGF- $\beta$ for 5 h, then stimulated with rlL-12 and rlL-15 for $24 \mathrm{~h}$. Representative flow-cytometry plots demonstrated the effect of rlL-10 or rTGF- $\beta$ on IFN- $\gamma$ secretion by NK cells (a). IFN- $\gamma$ secretion by NK cells was inhibited by different concentrations of rlL-10 (b) or rTGF- $\beta$ (c) and synergistically by treatment with both rlL-10 and rTGF- $\beta$ (d)
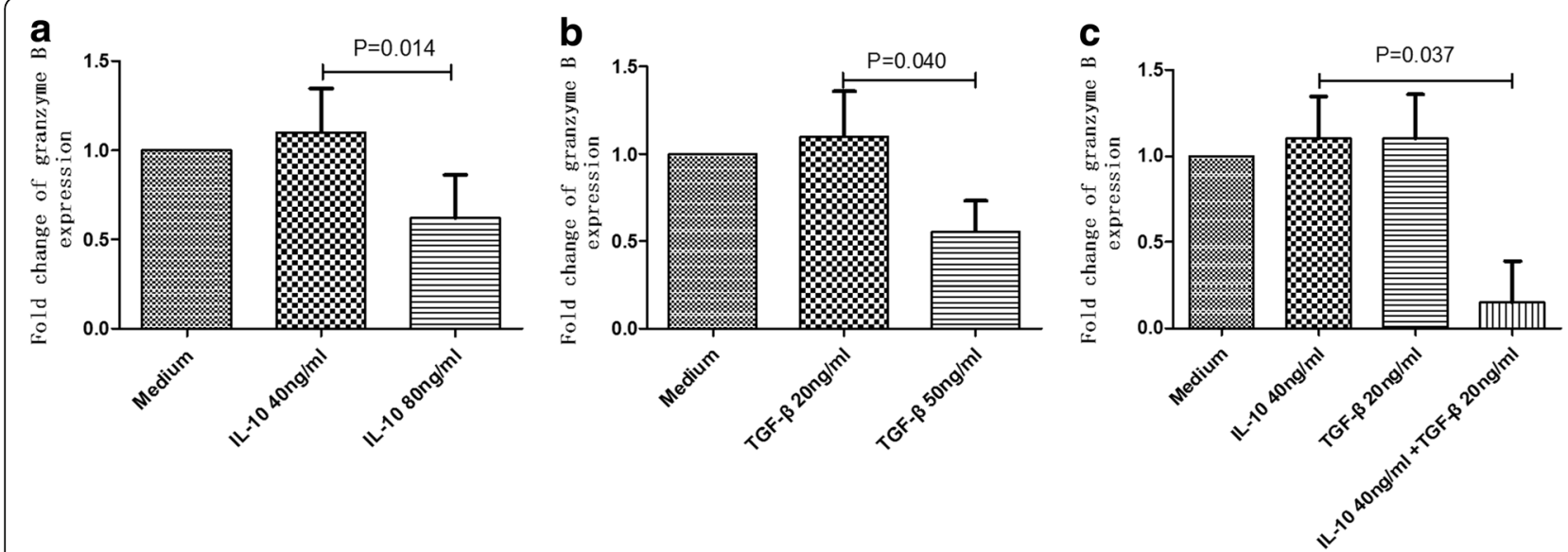

Fig. 7 Effects of rlL-10 and rTGF- $\beta$ on granzyme-B release by NK cellsPBMCs were co-cultured with rIL-10 and/or rTGF- $\beta$ for 5 h, and then stimulated with PMA and ionomycin for $6 \mathrm{~h}$. The inhibition of granzyme-B release by NK cells using different concentrations of rlL-10 (a) or rTGF- $\beta$ (b) was determined. The effect of treatment with both rIL-10 and rTGF- $\beta$ on granzyme-B release by NK cells was synergistic (c) 

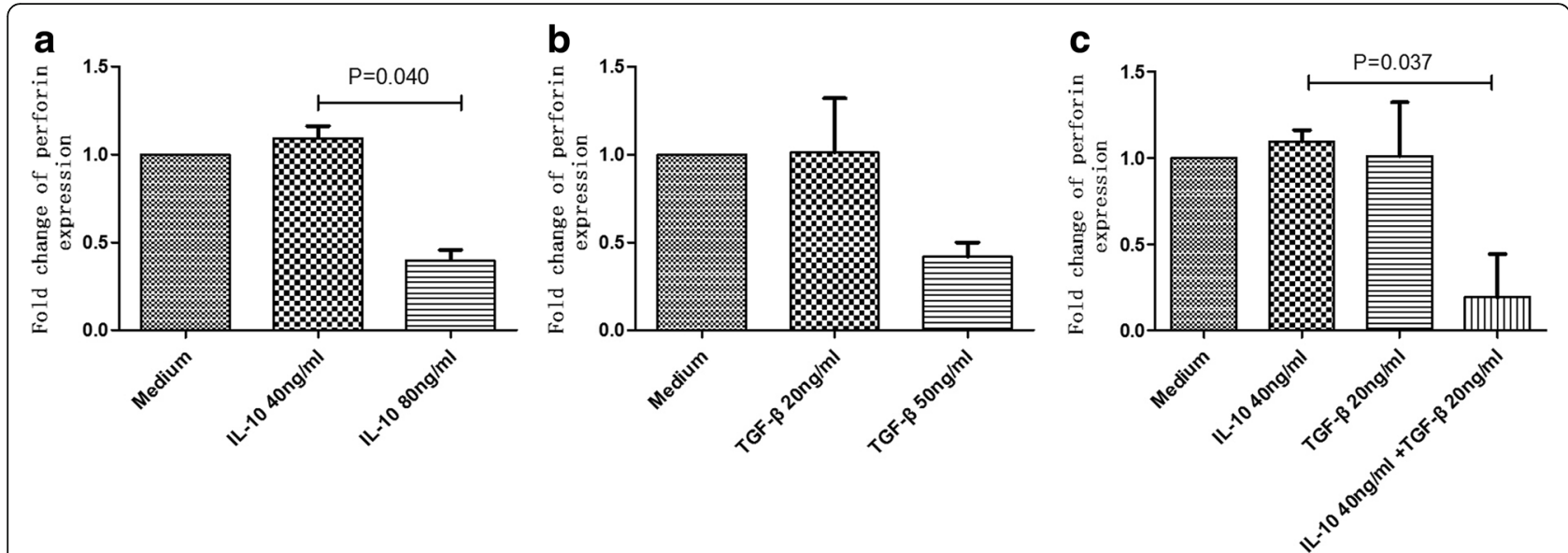

Fig. 8 Effects of rlL-10 and rTGF- $\beta$ on perforin release by NK cellsPBMCs were co-cultured with rIL-10 and/or rTGF- $\beta$ for 5 h, and then stimulated with PMA and ionomycin for $6 \mathrm{~h}$. The inhibition of perforin release by NK cells by different concentrations of rlL-10 (a) or rTGF- $\beta$ (b) was determined. The effects of treatment with both rlL-10 and rTGF- $\beta$ on perforin release by NK cells were synergistic (c)

generated similar results to those for $\mathrm{IL}-10^{+} \mathrm{NK}$ cells. These data indicate that ART is insufficient to induce complete recovery of immune functions, and that specific immune therapies are required to overcome the negative regulation. Our previous study showed that HIV infection can result in impaired NK cell functions, including diminished levels of perforin and IFN- $\gamma$ production [30,31], which may be related to negative regulation by cytokines. In the present study, the results of our in vitro experiments demonstrate that the expression of CD107a and secretion of IFN- $\gamma$ by NK cells can be inhibited by rIL-10 or rTGF- $\beta$. High concentrations of rIL-10 or rTGF- $\beta$ could also inhibit the release of granzyme B and perforin; therefore, we suspect that the increase in the percentage of $\mathrm{IL}-10^{+}$and TGF- $\beta^{+} \mathrm{NK}$ cells may be related to impaired NK cell cytotoxic function during HIV infection.

The mechanisms underlying the elevated percentage of IL- $10^{+}$and TGF- $\beta^{+}$NK cells during HIV infection remain unclear; however, it was reported that the HIV Env and Tat peptides are responsible for IL-10 production by $\mathrm{CD}^{+} \mathrm{T}$ cells [32-34], and the mitogen-activated protein kinase/extracellular signal-regulated kinase pathway was reported as involved in this process $[35,36]$. Further, in vitro experiments have indicated that HIV Tat can induce TGF- $\beta$ production by NK cells [21], and that TGF- $\beta$ may suppress NK cell functions by repressing the mTOR pathway [37], or inhibit IFN- $\gamma$ secretion and the ADCC response of NK cells via SMAD3-mediated signaling [38].

\section{Conclusions}

The results of our study demonstrate that the percentages of $\mathrm{IL}-10^{+}$and TGF- $\beta^{+}$NK cells are elevated in ART-naïve HIV-infected patients, and that ART-treated
HIV patients also have a high percentage of $\mathrm{IL}-10^{+} \mathrm{NK}$ cells. We also show that rIL-10 and/or rTGF- $\beta$ can inhibit the functions of NK cell effectors. Our research provides a potential therapeutic target for combating HIV infection, along with information useful for research into the pathogenesis and immunotherapy of HIV infection.

\section{Abbreviations \\ ADCC: Antibody-dependent cellular cytotoxicity; ART: Antiretroviral treatment; HCs: Healthy controls; HIV: Human immunodeficiency virus; IFN: Interferon; IL: Interleukin; NK: Natural killer; PBMCs: Peripheral blood mononuclear cells; rlL: Recombinant interleukin; rTGF- $\beta$ : Recombinant TGF- $\beta$; TGF- $\beta$ : Transforming growth factor- $\beta$}

\section{Acknowledgments}

The authors express their gratitude for the generosity of the patients who participated in this study.

\section{Funding}

Funding for this study was provided by the Mega Projects of National Science Research for the 12th Five-Year Plan (2014ZX10001002001004), and the Platform Project for Close Combination of Basic and Clinical Medicine (YIDA FAZI [2013] no. 5). The funding sources had no role in the study design, data collection, data analyses, preparation of the manuscript, or decision to publish.

\section{Availability of data and materials}

All data generated or analyzed during this study are included in this manuscript.

\section{Authors' contributions \\ $Y J$ and $\mathrm{HS}$ designed the experiments, interpreted the data, and wrote the manuscript. MY, XS, XC, MM, XY, SQ, and YJ carried out the NK cell experiments. ZZ and YF carried out $\mathrm{CD}^{+} \mathrm{T}$ cell counts. $\mathrm{XH}$ participated in measurement of HIV viral load. JX and JL carried out the epidemiological study and helped to recruit study participants. All authors have read and approved the manuscript.}

\section{Ethics approval and consent to participate}

The Medical Science Research Ethics Committee of the First Affiliated Hospital of China Medical University (Shenyang, China) approved the study protocol (KELUNSHEN [2011] number 36). Our study was conducted according to the principles enshrined in the Declaration of Helsinki. Written 
informed consent to take part in the study was obtained from all participants.

\section{Consent for publication \\ Not applicable.}

\section{Competing interests}

The authors declare that they have no competing interests.

\section{Publisher's Note}

Springer Nature remains neutral with regard to jurisdictional claims in published maps and institutional affiliations.

\section{Author details}

${ }^{1}$ Key Laboratory of AIDS Immunology of National Health and Family Planning Commission, Department of Laboratory Medicine, The First Affiliated Hospital, China Medical University, No. 155, Nanjingbei Street, Heping District, Shenyang, Liaoning Province 110001, China. ${ }^{2}$ Collaborative Innovation Center for Diagnosis and Treatment of Infectious Diseases, 79 Qingchun Street, Hangzhou, China. ${ }^{3}$ Clinical Laboratory, Shenyang Women and Children's Hospital, Shenyang, China.

Received: 6 December 2016 Accepted: 7 February 2018

\section{Published online: 13 February 2018}

\section{References}

1. Cacalano NA. Regulation of natural killer cell function by STAT3. Front Immunol. 2016;7:128

2. Littwitz-Salomon E, Dittmer U, Sutter K. Insufficient natural killer cell responses against retroviruses: how to improve NK cell killing of retrovirusinfected cells. Retrovirology. 2016;13(1):77.

3. Chester C, Fritsch K, Natural KHE. Killer cell immunomodulation: targeting activating, inhibitory, and co-stimulatory receptor signaling for cancer immunotherapy. Front Immunol. 2015:6:601.

4. Caligiuri MA. Human natural killer cells. Blood. 2008;112(3):461-9.

5. Cooper MA, Fehniger TA, Turner SC, Chen KS, Ghaheri BA, Ghayur T, et al. Human natural killer cells: a unique innate immunoregulatory role for the CD56(bright) subset. Blood. 2001;97(10):3146-51.

6. Cooper MA, Fehniger TA, Caligiuri MA. The biology of human natural killercell subsets. Trends Immunol. 2001;22(11):633-40.

7. Laouar Y, Sutterwala FS, Gorelik L, Transforming FRA. Growth factor-beta controls $T$ helper type 1 cell development through regulation of natural killer cell interferon-gamma. Nat Immunol. 2005;6(6):600-7.

8. Eriksson M, Meadows SK, Wira CR, Unique SCL. Phenotype of human uterine NK cells and their regulation by endogenous TGF-beta. J Leukoc Biol. 2004; 76(3):667-75.

9. Ostapchuk YO, Cetin EA, Perfilyeva Y, et al. Peripheral blood NK cells expressing HLA-G, IL-10 and TGF-beta in healthy donors and breast cancer patients. Cell Immunol. 2015:298(1-2):37-46.

10. Elrefaei M, Burke CM, Baker CA, et al. TGF-beta and IL-10 production by HIVspecific CD8+ T cells is regulated by CTLA-4 signaling on CD4+ T cells. PLOS One. 2009:4(12):e8194.

11. Shete A, Suryawanshi P, Godbole S, Pawar J, Paranjape R, Thakar M. HIVinfected CD4+ T cells use T-bet-dependent pathway for production of IL-10 upon antigen recognition. Scand J Immunol. 2016;83(4):288-96.

12. Wagage $\mathrm{S}$, John $\mathrm{B}$, Krock $\mathrm{BL}$, et al. The aryl hydrocarbon receptor promotes IL-10 production by NK cells. J Immunol. 2014;192(4):1661-70.

13. Perona-Wright G, Mohrs K, Szaba FM, et al. Systemic but not local infections elicit immunosuppressive IL-10 production by natural killer cells. Cell Host Microbe. 2009:6(6):503-12.

14. $\mathrm{Ng} \mathrm{CT}$, Oldstone MB. Infected CD8alpha- dendritic cells are the predominant source of IL-10 during establishment of persistent viral infection. Proc Natl Acad Sci U S A. 2012;109(35):14116-21.

15. Gray JD, Hirokawa M, Ohtsuka K, Horwitz DA. Generation of an inhibitory circuit involving CD8+ T cells, IL-2, and NK cell-derived TGFbeta: contrasting effects of anti-CD2 and anti-CD3. J Immunol. 1998; 160(5):2248-54

16. Sporn MB, Roberts AB, Wakefield LM, de Crombrugghe B. Some recent advances in the chemistry and biology of transforming growth factor-beta. J Cell Biol. 1987;105(3):1039-45.
17. Wahl SM. Transforming growth factor beta: the good, the bad, and the ugly. J Exp Med. 1994;180(5):1587-90.

18. Clerici M, Wynn TA, Berzofsky JA, et al. Role of interleukin-10 in T helper cell dysfunction in asymptomatic individuals infected with the human immunodeficiency virus. J Clin Invest. 1994;93(2):768-75.

19. Fidler SJ, Antigen RAD. Presenting cell function in HIV-1 infected patients. Immunol Lett. 1999;66(1-3):129-34

20. Schols D, De Clercq E. Human immunodeficiency virus type 1 gp120 induces anergy in human peripheral blood lymphocytes by inducing interleukin-10 production. J Virol. 1996;70(8):4953-60.

21. Poggi A, Zocchi MR. HIV-1 tat triggers TGF-beta production and NK cell apoptosis that is prevented by pertussis toxin B. Clin dev immunol. 2006; 13(2-4):369-72.

22. Brooks DG, Trifilo MJ, Edelmann KH, Teyton L, McGavern DB, Oldstone MB. Interleukin-10 determines viral clearance or persistence in vivo. Nat Med. 2006;12(11):1301-9.

23. Park JY, Lee $\mathrm{SH}$, Yoon SR, et al. IL-15-induced IL-10 increases the cytolytic activity of human natural killer cells. Molec cells. 2011;32(3):265-72.

24. Moore KW, de Waal Malefyt R, Coffman RL, O'Garra A. Interleukin-10 and the interleukin-10 receptor. Annu Rev Immunol. 2001;19:683-765.

25. Hamidullah, Changkija B, Konwar R. Role of interleukin-10 in breast cancer. Breast Cancer Res Treat. 2012:133(1):11-21.

26. Crane CA, Han SJ, Barry JJ, Ahn BJ, Lanier LL, TGF-beta PAT. Downregulates the activating receptor NKG2D on NK cells and CD8+ T cells in glioma patients. Neuro-Oncology. 2010;12(1):7-13.

27. Wilson EB, El-Jawhari Jل Jeilson AL, et al. Human tumour immune evasion via TGF-beta blocks NK cell activation but not survival allowing therapeutic restoration of anti-tumour activity. PLoS One. 2011;6(9):e22842.

28. Taylor A, Verhagen J, Blaser K, Akdis M, Mechanisms ACA. Of immune suppression by interleukin-10 and transforming growth factor-beta: the role of T regulatory cells. Immunology. 2006;117(4):433-42.

29. Brockman MA, Kwon DS, Tighe DP, et al. IL-10 is up-regulated in multiple cell types during viremic HIV infection and reversibly inhibits virus-specific T cells. Blood. 2009;114(2):346-56

30. Jiang $Y$, Zhou F, Tian Y, et al. Higher NK cell IFN-gamma production is associated with delayed HIV disease progression in LTNPs. J Clin Immunol. 2013:33(8):1376-85.

31. Qi W, Yongjun J, Yanan W, et al. Differential expression of perforin in cytotoxic lymphocyte in HIV/AIDS patients of China. J Clin Immunol. 2006; 26(4):339-46.

32. Shete A, Thakar M, Singh DP, et al. Short communication: HIV antigenspecific reactivation of HIV infection from cellular reservoirs: implications in the settings of therapeutic vaccinations. AIDS Res Hum Retrovir. 2012;28(8): 835-43.

33. Badou A, Bennasser Y, Moreau M, Leclerc C, Benkirane M, Tat BE. Protein of human immunodeficiency virus type 1 induces interleukin-10 in human peripheral blood monocytes: implication of protein kinase C-dependent pathway. J Virol. 2000;74(22):10551-62.

34. Bennasser $Y$, Bahraoui E. HIV-1 tat protein induces interleukin-10 in human peripheral blood monocytes: involvement of protein kinase C-betall and -delta. FASEB j : offi pub Feder Am Soc Exper Biol. 2002;16(6):546-54.

35. Gee K, Angel JB, Ma W, et al. Intracellular HIV-tat expression induces IL-10 synthesis by the CREB-1 transcription factor through Ser133 phosphorylation and its regulation by the ERK1/2 MAPK in human monocytic cells. J Biol Chem. 2006:281(42):31647-58.

36. Saraiva M, Christensen JR, Veldhoen M, Murphy TL, Murphy KM, O'Garra A. Interleukin-10 production by Th1 cells requires interleukin-12-induced STAT4 transcription factor and ERK MAP kinase activation by high antigen dose. Immunity. 2009:31(2):209-19.

37. Viel S, Marcais A, Guimaraes FS, et al. TGF-beta inhibits the activation and functions of NK cells by repressing the mTOR pathway. Sci Signal. 2016: 9(415):ra19.

38. Trotta R, Dal Col J, Yu J, et al. TGF-beta utilizes SMAD3 to inhibit CD16mediated IFN-gamma production and antibody-dependent cellular cytotoxicity in human NK cells. J Immunol. 2008;181(6):3784-92. 